\title{
Psychoeducation versus treatment as usual in diabetic patients with subthreshold depression: preliminary results of a randomized controlled trial
}

\author{
Mirjana Pibernik-Okanovic*1, Drazen Begic ${ }^{2}$, Dea Ajdukovic ${ }^{1}$, \\ Natasa Andrijasevic ${ }^{1}$ and Zeljko Metelko ${ }^{1}$
}

Address: ${ }^{V}$ Vuk Vrhovac University Clinic, Dugi dol 4a, Zagreb, Croatia and ${ }^{2}$ Rebro University Hospital, Kispaticeva 12, Zagreb, Croatia Email: Mirjana Pibernik-Okanovic* - pibernik@idb.hr; Drazen Begic - dbegic@yahoo.com; Dea Ajdukovic - dea.ajdukovic@idb.hr; Natasa Andrijasevic - andrijasevic@idb.hr; Zeljko Metelko - Zeljko.Metelko@idb.hr

* Corresponding author

Published: 26 August 2009

Trials 2009, 10:78 doi:10.1186/1745-6215-10-78

This article is available from: http://www.trialsjournal.com/content/I0/I/78

(C) 2009 Pibernik-Okanovic et al; licensee BioMed Central Ltd.

This is an Open Access article distributed under the terms of the Creative Commons Attribution License (http://creativecommons.org/licenses/by/2.0), which permits unrestricted use, distribution, and reproduction in any medium, provided the original work is properly cited.
Received: 15 May 2009

Accepted: 26 August 2009

\begin{abstract}
Background: Research on the effects of treating sub-threshold depression in persons with diabetes is scarce in spite of the findings indicating that this condition is highly prevalent in the diabetic population and may increase the risk of developing a subsequent major depression. This study was aimed at exploring the effects of a psycho-educational intervention on depression- and diabetes-related outcomes in patients with mild to moderate depressive symptoms.

Methods: A randomized controlled study design with a one-year follow-up was used. Fifty patients with mild to moderate depressive symptoms ( $74 \%$ female, aged $57 \pm 9$ yrs, diabetes duration of 10 $\pm 8 \mathrm{yrs}, \mathrm{BMI} 3 \mathrm{I} \pm 6 \mathrm{~kg} / \mathrm{m}^{2}, \mathrm{HbAIC} 7.7 \% \pm 1.4,53 \%$ insulin treated) were randomly assigned to either an intervention or a control group. The intervention group underwent four psychoeducational sessions aimed at enabling self-management of depressive symptoms. The control group was informed about the screening results and depression treatment options while continuing diabetes treatment as usual. Both groups were contacted by phone in 2-3-month intervals, and reassessed for depression after 6 and 12 months. Changes in depressive symptoms and glycaemic control were considered primary outcomes. Mann-Whitney $U$ test and Friedman ANOVA were used to compare between- and within-group indicators at 6- and I2-month follow-ups.
\end{abstract}

Results: Both the intervention and the control group reported a significant decrease in depressive symptoms as measured by the CES-D scale (Friedman ANOVA $\chi^{2}=10.8 \mathrm{p}=.004$ and $\chi^{2}=7.3 \mathrm{p}$ $=0.03$, respectively). The 6-month and I-year indicators of glycaemic control as compared to baseline $\mathrm{HbAIC}$ values were also improved in both groups $\left(\chi^{2}=11.6 \mathrm{p}=0.003\right.$ and $\chi^{2}=17.1 \mathrm{p}=$ 0.0002 , respectively). Between-group differences in depressive symptoms and $\mathrm{HbAIC}$ values were not statistically significant either at 6- or at 12-month follow-up (all $p>0.05$ ).

Conclusion: Psycho-educational treatment appears to be beneficial in diabetic patients with mild to moderate depressive symptoms, but its effects are comparable with the non-specific support given to the subjects in the control group.

Trial registration: Current Controlled Trials ISRCTN58745372 


\section{Background}

The prevalence of depression in diabetes is approximately twice as high as in the general population [1], implying a synergistic interaction between the two conditions that increases the risk of poor health outcomes [2].

In comparison with patients with diabetes alone, patients with both diabetes and depression have been shown to have poorer self-management (i.e. adherence to diet, exercise regimen and blood glucose monitoring) and significantly more lapses in refilling oral hypoglycaemic, lipidlowering and antihypertensive prescriptions $[3,4]$. Depressed patients with diabetes are also significantly more likely to have cardiac risk factors such as smoking, obesity and sedentary lifestyle, compared to those with diabetes alone [5]. Depression is associated with an increased risk of metabolic dysregulation [6], micro- and macrovascular complications [7], and mortality [8].

Not only clinical depression but also its sub-threshold forms have been shown to have a profound influence on the affected patients' quality of life [9]. Defined as the presence of depressive symptoms that fall short of full diagnostic criteria for major depression or dysthymia, sub-threshold depression may be considered to be a part of a continuum of depressive disorders [10]. Judd et al. [11] conceptualized unipolar depression as presenting in different degrees of severity along a spectrum, with subthreshold depression being the mildest form along the spectrum. It may represent a discrete category of its own but may also represent a prodromal, residual or interepisode symptomatic state in the course of major depression [12]. Data from the general population indicate that spontaneous improvement for this type of depression is low [13]. A systematic review of the literature on the prognosis of minor depression [14] showed that 16-62.3\% individuals with sub-threshold depressive symptoms still have a minor depression after 5 months to 1 year of follow-up, suggesting that for many people this form of depression is chronic or recurrent. Sub-threshold depression has been found to increase the risk of subsequent major depression [15] and suicide [16]. Recent studies have uncovered some predictors of conversion from minor depression into its more severe clinical forms, chronic illness and medical burden being shown to be among them $[17,18]$.

As research on treatments for sub-threshold depression in diabetic patients is scarce, data on their hypothetical effects on depression- and diabetes-related outcomes are inconclusive. There has been only one small randomized placebo-controlled pilot study of pharmacological treatment conducted in 15 mildly depressed women with type 2 diabetes [19], its results indicating beneficial treatment effects on insulin sensitivity. A small non-randomized study of the effects of a psycho-educational intervention on mood and glycaemic control in adults with diabetes and visual impairment [20] has shown positive effects on diabetes-related distress as measured by the Problem Areas in Diabetes scale, and on glycaemic control. The study has demonstrated significant positive correlation between glycaemic control and improvement in depression. Both of these studies have employed small sample sizes and study designs that do not allow reliable conclusions about the clinical benefits of treating sub-threshold depression in persons with diabetes.

The hypothesis of this study was that screening depressive symptoms in diabetic patients attending their regular medical check-ups, and including those with sub-threshold depression in a psychoeducational intervention accompanied by a structured follow-up, might have positive effects on depression- and diabetes-related outcomes as defined as improvement of depressive symptoms and glycaemic control. The study was expected to remedy methodological inadequacies inherent to previous studies in the field using a randomized controlled study design with a one-year follow-up. It was aimed at comparing the effects of the psycho-educational intervention in diabetic patients with mild to moderate depressive symptoms with those of standard diabetes care including screening for depression and a structured follow-up.

In this paper we present baseline and one-year follow-up data of 50 patients randomly assigned to the two groups.

\section{Methods}

Diabetic patients attending their regular check-ups at the Vuk Vrhovac University Clinic for Diabetes, Endocrinology and Metabolic Diseases, a referral centre for the registration, treatment and follow-up of patients with diabetes in Croatia, were screened for depression by using the Patient Health Questionnaire (PHQ-9). Patients with scores of 10-14 points, which indicated mild to moderate depression [21], were the trial's target group. A history of poor literacy, mobility difficulties, visual impairment, drinking problems, co-morbid organic psychiatric disorder or psychosis was considered as the exclusion criteria.

The eligible patients were explained the purpose of the study and requested to give written consent to participate. Patients who were willing to be included were randomized to either the intervention or the control group by means of sequentially numbered sealed envelopes. Patients who refused to participate in the research received their usual diabetes care and were excluded from this study.

Participants in the intervention arm were included in a psycho-educational programme consisting of four interac- 
tive group sessions. The control subjects continued to receive standard diabetes care while being informed about the outcomes of the performed screening procedure, and about available treatment modalities. Both groups were followed for one year including re-assessments of depressive symptoms and glycaemic control at 6 and 12 months, and telephone calls in 2- to 3-month intervals to check on patients' actions in managing depression.

At baseline, the study participants were interviewed using a semi-structured interview inquiring about their psychological history (past psychological morbidity, method of treatment, course of symptoms, psychological morbidity in family members) and present psychosocial situation (family status, professional status, economic circumstances, recent stressful experiences, perceived social support).

Psychological questionnaires Center for Epidemiologic Studies Depression Scale [22], Problem Areas in Diabetes [23] scale, health-related quality of life questionnaire [24] and Summary of Diabetes Self-Care Activities [25] were applied to collect data about patients' emotional state and their experience in living with diabetes. The questionnaires were previously psychometrically evaluated in Croatian diabetic patients.

The Centre for Epidemiological Studies Depression (CESD) scale is a 20-item, self-report scale that asks respondents to indicate the frequency of experiencing each of the 20 symptoms over the previous week. The instrument uses a 4-point response scale ranging from "rarely or none of the time" to "most or all of the time" with total scores ranging from 0 to 60 . Higher scores indicate more severe depressive symptoms. A cut-point of $\geq 16$ was considered indicative of elevated depressive symptoms.

The Problem Areas in Diabetes (PAID) questionnaire is a 20-item, self-report scale that asks respondents to rate how much of a problem they find each of the 20 diabetesrelated issues. The answers are given on a 5-point scale ranging from 0 ("not a problem") to 4 ("serious problem"). The PAID scores are summed (with total scores ranging from 0 to 80 ) and transformed to a $0-100$ scale with higher scores indicating more diabetes-related distress. Scores $>40$ were considered indicative of high distress.

The short-form health survey (SF-12 v2) comprises selfassessments of general health, physical functioning, physical roles, bodily pain, vitality, social functioning, emotional roles and mental health. The raw scores for particular subscales are transformed to a $0-100$ scale with higher scores indicating better health-related quality of life.
The Summary of Diabetes Self-Care Activities (SDSCA) is a brief self-report questionnaire of diabetes self-management that includes items assessing general diet, specific diet, exercise, blood glucose testing, foot care and smoking. The questionnaire asks the respondents about the frequency with which they performed self-care activities over the previous 7 days. Higher subscale scores indicate more regular performing of the self-care activities included.

Medical data were collected from the patients' medical records. $\mathrm{HbA}_{1 \mathrm{c}}$ was determined by an automated immunoturbidimetric method using Bayer reagents (Tarrytown, Il, USA) on Olympus AU600 analyser (Olympus Optical Co., Tokyo, Japan) with a normal range from 3.5 to $5.7 \%$ [26].

\section{The intervention arm}

\section{Psycho-education on depression}

The psycho-educational intervention comprised 4 interactive small group meetings, each lasting for 90 minutes, on the following topics:

- Symptoms of depression; interaction of depression and diabetes;

- Alleviating burden of depression through activities and problem solving;

- Associations between depression and cognitive processes - thoughts, beliefs and attitudes that induce and maintain depression; and

- Developing a personal plan for managing depressionrelated problems in the future.

The first two meetings were held within a week of each other, and the third and the fourth at two-week intervals. Patients were provided with a self-help manual for overcoming depressive difficulties based on the "Coping with depression" course by P.M. Lewinsohn $[27,28]$. The manual was given to the participating patients prior to the first session in order to make them familiar with the course contents and to facilitate reflecting their own experiences. The manual's structure aimed to stimulate introducing personal examples and making notes. The group sessions consisted of discussing particular topics rather than listening about them. A part of the manual was a workbook containing exercises to recognize depressive symptoms, become aware of daily activity patterns, plan more pleasurable activities, solve problems by using a four-step approach, and to recognize and modify cognitive patterns that contribute to maintenance of depression. The exercises were planned as homework. It included keeping mood and daily activities diary, planning daily activities to include more enjoyable ones, practicing a problem 
solving technique to manage personal problems the patients were faced with, and using the acquired knowledge to improve self-awareness, primarily with respect to automatic negative thoughts that worsen the depressive mood. The patients' experiences in going through the homework were discussed at the beginning of the subsequent session.

The manual was tested for comprehensibility and clarity in a group of diabetic patients $(\mathrm{N}=8)$ with different demographic and disease-related characteristics. For the purpose of this study, the programme was partially modified and adjusted to diabetes-specific emotional problems.

\section{The control arm}

Depression screening followed by standard diabetes treatment

The patients screened for depression demonstrating elevated result were given explanation of their result and were informed about available treatment options. The control participants were contacted by phone at the same intervals as the patients from the intervention group, and re-assessed for psychological variables after 6 and 12 months.
Sample size calculation was based on the absolute change in depressive symptoms as measured by the CES-D questionnaire from the run-in period to the 6- and 12-month follow-up assessments. To demonstrate a clinically meaningful difference in the CES-D scores with alpha $=0.05$ and power of $90 \%$, and assuming a common standard deviation of the CES-D scores of 8.4, 94 patients would be needed in each group.

These preliminary results were analysed using non-parametric statistics including medians and modes to describe measures of central tendencies and variability, MannWhitney $U$ test to determine between-group differences at the three measurement points, and the Friedman ANOVA test to determine within-group differences in depressionrelated and metabolic outcomes.

\section{Ethical approval}

The study was approved by the Vuk Vrhovac Clinic Ethics committee.

\section{Results}

Demographic, disease-related and psychological characteristics of the intervention and the control group are presented in Table 1. The two groups were comparable with

Table I: Demographic, disease-related and psychological characteristics of the patients from the intervention and the control groups

\begin{tabular}{|c|c|c|c|c|}
\hline & $\begin{array}{l}\text { Intervention group } \\
\text { Median (25-75) }\end{array}$ & $\begin{array}{l}\text { Control group } \\
\text { Median (25-75) }\end{array}$ & $\mathbf{Z}$ & $\mathbf{p}$ \\
\hline Age (yrs) & $55(5 \mid-62)$ & $58(53-64)$ & -1.1 & 0.27 \\
\hline Female (\%) & 64 & 84 & & 0.11 \\
\hline Education (yrs) & $12(8-14)$ & II (8-II) & 2.52 & $0.01 * *$ \\
\hline Diabetes duration (yrs) & $10(3-14.5)$ & $10.5(4.5-13.5)$ & -0.51 & 0.61 \\
\hline Body mass index $\left(\mathrm{kg} / \mathrm{m}^{2}\right)$ & $30.8(26.7-35.8)$ & $30.9(27.9-30.4)$ & 0.25 & 0.80 \\
\hline HbAIC (\%) & $7.5(6.4-8.3)$ & $7.7(6.6-8.9)$ & -0.42 & 0.68 \\
\hline PHQ-9 (score) & $13(11-18)$ & $13(11-15)$ & 0.23 & 0.81 \\
\hline CES-D (score) & $26(22-30)$ & $24(18-35)$ & 1.03 & 0.31 \\
\hline PAID (total score) & $51(33-60)$ & $45(25-58)$ & 0.91 & 0.36 \\
\hline Negative emotions & $56(33-67)$ & $48(21-63)$ & 0.86 & 0.40 \\
\hline Treatment & $33(17-50)$ & $33(17-50)$ & $-0,23$ & 0.82 \\
\hline Food & $42(33-75)$ & $58(33-75)$ & -0.03 & 0.98 \\
\hline Social support & $38(13-63)$ & $13(0-50)$ & 1.49 & 0.14 \\
\hline SDSCA-diet & $4(3-6)$ & $4(3-6)$ & 0.07 & 0.94 \\
\hline -specific diet & $3.5(2-5.5)$ & $5.5(3.5-7)$ & -2.11 & $0.03 *$ \\
\hline -exercise & $3.25(1.5-5)$ & $3(I-3.5)$ & 0.75 & 0.43 \\
\hline -blood glucose monitoring & $7(0.75-5.25)$ & $6.5(0.5-7)$ & 0.69 & 0.49 \\
\hline -foot care & $3.5(0-7)$ & $2.5(0-7)$ & 0.51 & 0.61 \\
\hline SF - General health & $25(0-25)$ & $25(0-50)$ & -0.06 & 0.95 \\
\hline Physical functioning & $37.5(25-50)$ & $17(0-37.5)$ & 2.36 & $0.02 *$ \\
\hline Role physical & $50(25-62.75)$ & $50(31.25-62.5)$ & 0.08 & 0.94 \\
\hline Role emotional & $50(50-50)$ & $50(32-62.5)$ & -0.30 & 0.77 \\
\hline Bodily pain & $50(25-62.5)$ & $25(25-75)$ & -0.05 & 0.96 \\
\hline Mental health & $38(25-50)$ & $38(25-50)$ & -0.45 & 0.65 \\
\hline Vitality & $25(25-50)$ & $50(25-50)$ & -1.22 & 0.22 \\
\hline Social functioning & $37.5(25-50)$ & $50(25-75)$ & -1.78 & 0.07 \\
\hline
\end{tabular}

** significant at $99 \%$ confidence level

$*$ significant at $95 \%$ confidence level 
respect to age, gender, diabetes duration, body mass index, glycaemic control, depressive symptoms and diabetes-related emotional problems (all p > 0.05). Healthrelated quality of life was comparable in both groups with the exception of physical functioning which was shown to be slightly better in the intervention group $(\mathrm{p}=0.02)$. Self-reported diabetes self-care was similar in both groups with respect to healthy eating, exercise, blood glucose selfmonitoring and foot care (all p > 0.05). Adherence to diabetes-specific diet seemed to be greater in the control group $(\mathrm{p}=0.03)$. The intervention group had a higher level of education than the control group $(p=0.01)$.

Between-group differences at the 6- and 12-month followup visits are presented in Table 2.

Both the intervention and the control group reported less depressive symptoms at the follow-up assessments and had better glycaemic control as compared to baseline indicators. The between-group differences were not statistically significant either at 6 - or at 12 -month follow-ups.

Changes in depressive symptoms and $\mathrm{HbA} 1 \mathrm{C}$ values for the intervention group are presented in Figures 1 and 2. Friedman ANOVA indicated that individuals treated with psycho-educational intervention reported improved depressive symptoms at the 6-month assessment and remained so after 12 months $(\mathrm{p}=0.004)$. The same trend could be observed for HbA1C values which were significantly lower at the follow-up assessments, showing an average decrease of $0.5 \%(p=0.0003)$.

Changes in depression-related outcomes and glycaemic control for the control group are presented in Figures 3 and 4 . Like the intervention group, the control subjects improved their depressive symptoms and HbA1C at 6and 12-month follow-up assessments $(\mathrm{p}=0.03$ and $\mathrm{p}=$ 0.0002 respectively).

\section{Discussion}

The preliminary data on the effects of the psycho-educational intervention in patients with mild to moderate depressive symptoms do not support its effectiveness in comparison with the non-specific support given to the control patients. A comparable improvement in depressive symptoms observed in the patients who were included in the psycho-educational group sessions, and in those who were only screened for depression and then followed for one year might suggest that treating sub-threshold forms of depression does not demonstrate a clear clinical utility. Such a conclusion might be additionally supported by the finding that both the intervention and the control participants demonstrated a similar improvement in glycaemic control at 6- and 12-month follow-up assessments. These findings suggest that the patients included in the study benefited in terms of improved mood and glycaemic control regardless of the study arm.

There are two hypothetical explanations of the results obtained. The first one concerns the structure of the control arm. Although defined as "diabetes treatment as usual" it actually implied a more supportive approach than diabetic patients usually receive within their standard care. Screening for depression and discussing the results with the patients may be considered a kind of an intervention as well. As shown by Pouwer et al. [29], monitoring and discussing psychological well-being as part of routine diabetes outpatient care had favourable effects on the patients' mood. Besides monitoring, the control participants in our trial received several telephone calls during the follow-up period, and were invited for depression reassessment after 6 and 12 months. This could have been experienced as an additional support possibly affecting the obtained results. Qualitative data on patients' experiences with participating in the trial collected at the end of the follow-up period support the hypothesis on the beneficial effect of monitoring patients' mood within standard diabetes care.

Table 2: Comparisons of depressive symptoms and glycaemic control between the intervention and the control group at 6 and 12 months

\begin{tabular}{|c|c|c|c|c|}
\hline & Absolute change: Intervention versus Control group & $U$ & z & $\mathrm{P}$ \\
\hline Depressive symptoms at 6 months (CES-D scores) & $\begin{array}{c}26(22-30) \text { to } 18(12.5-28.5) \text { versus } 24(18-35) \text { to } 20 \\
(16.5-27)\end{array}$ & 264.5 & -0.49 & 0.63 \\
\hline Depressive symptoms at 12 months (CES-D scores) & $26(22-30)$ to $19(11-26)$ versus $24(18-35)$ to $19(15-26)$ & 295.5 & -0.33 & 0.74 \\
\hline Glycaemic control at 6 months $\left(\mathrm{HbA}_{1} \mathrm{C}\right)$ & $\begin{array}{c}7.5(6.4-8.3) \text { to } 7.3(6.3-7.6) \text { versus } 7.7(6.6-8.9) \text { to } 6.9 \\
(6.2-8.2)\end{array}$ & 279.0 & 0.19 & 0.86 \\
\hline Glycaemic control at I 2 months $\left(\mathrm{Hb}_{\mathrm{A}} \mathrm{C}\right)$ & $\begin{array}{c}7.5(6.4-8.3) \text { to } 7.0(6.0-7.6) \text { versus } 7.7(6.6-8.9) \text { to } 7.0 \\
(5.9-7.9)\end{array}$ & 293.5 & -0.13 & 0.89 \\
\hline
\end{tabular}




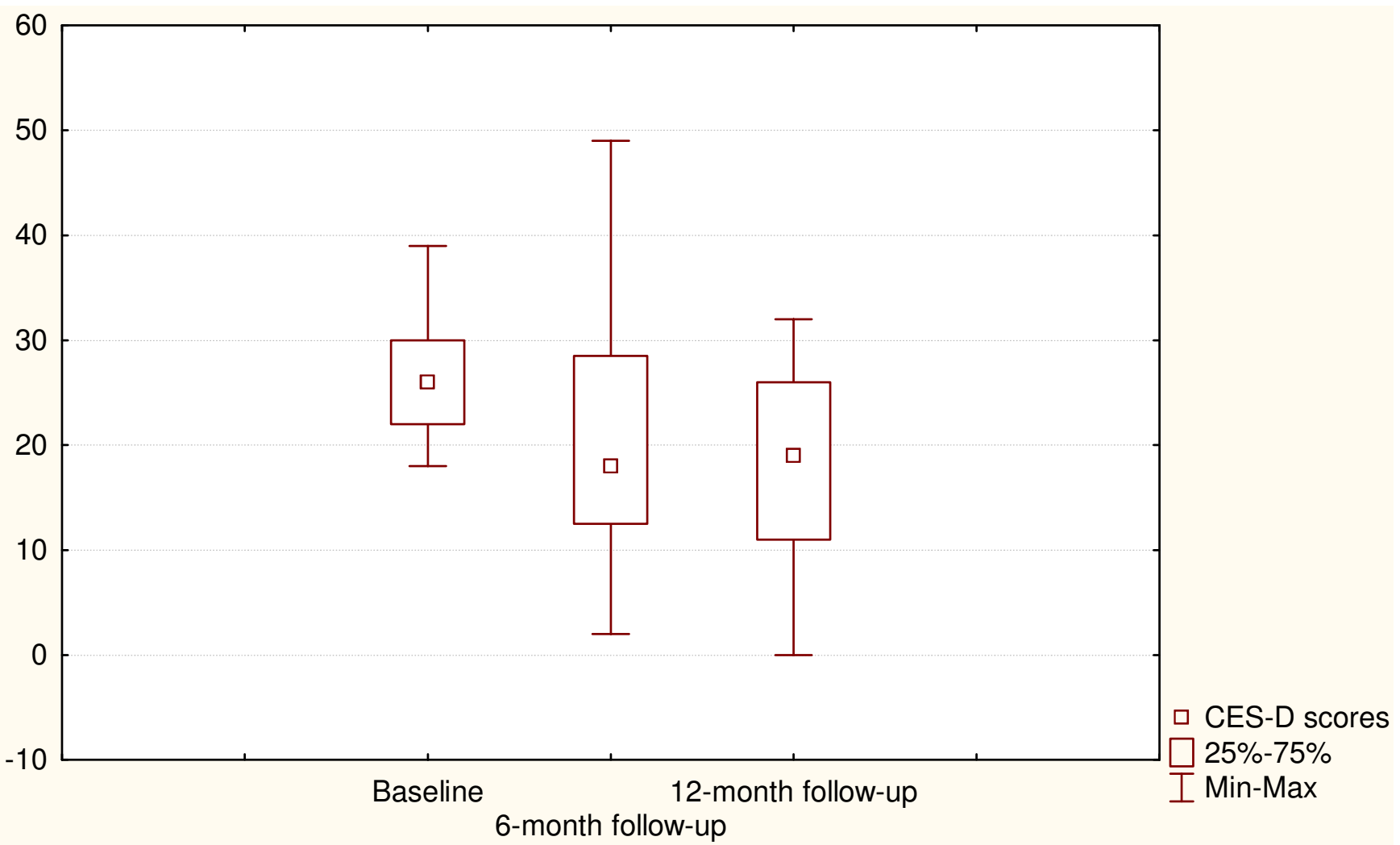

Figure I

Depressive symptoms at baseline and after 6- and I 2-month follow-up (Intervention arm). $X^{2}=10.8, p=0.004$, Coefficient of concordance $=0.27$, Average rank correlation $=0.23$.

The second explanation of the obtained results concerns the intervention format and content. A short intervention used in the trial relied on cognitive-behavioural principles. It aimed to stimulate patients' activation and improve their capabilities to actively participate in solving their internal and external problems. However, some individuals found participation in group sessions and exercises difficult. Possibly due to their demographic characteristics (middle age, relatively low level of education, limited objective resources) they perceived engagement in psychological processes they had not previously practiced as difficult. Their ambivalence towards experimenting with new cognitive patterns might be even increased by the fact that, although agreeing to the intervention, they actually would not choose it if it were not recommended. Being asked about subjectively perceived benefits of the intervention at the end of the follow-up, some patients pointed out the new skills they learned, but the majority found the experienced support to be most helpful.

Qualitative data collected from the intervention and the control subjects allow a hypothesis that the two study arms had at least one common component, described by the patients as a sense of being supported and cared for, and that this component itself seems to be helpful in addressing sub-threshold depression in patients with diabetes.

Another relevant finding obtained in the study was that the intervention and the control groups comparably improved $\mathrm{HbA} 1 \mathrm{C}$ values after 6 - and 12-month follow-up periods indicating an inverse relation between depressive symptoms and glycaemic control. At present, the relationship between depressive symptoms and glycaemic control is still not fully understood. Some studies have proved an undesirable association between depressive symptoms and metabolic indicators [6] but others did not confirm such an association [30,31]. Effects of treating depressed diabetic individuals on their glycaemic control are also a matter of debate, with controversial reports on the association between metabolic improvement and reduction in depressive symptoms [32,33].

Our preliminary data suggest that focusing on patients' emotional state either in the form of a psycho-educational 


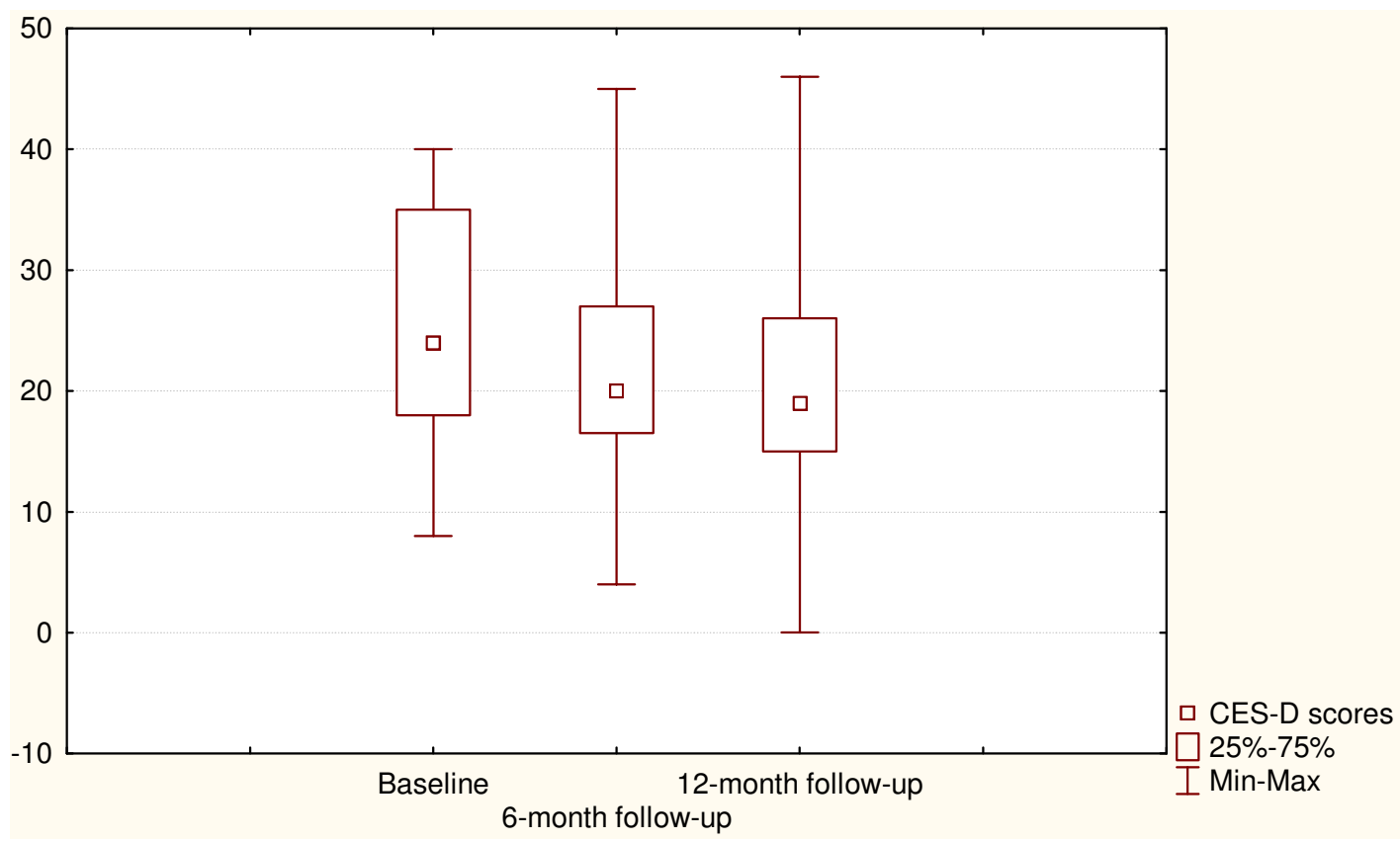

Figure 2

Depressive symptoms at baseline and after 6- and I 2-month follow-up (Control arm). $\mathrm{X}^{2}=7.3, \mathrm{p}=0.03, \mathrm{Coeffi}-$ cient of concordance $=0.19$, Average rank correlation $=0.15$.

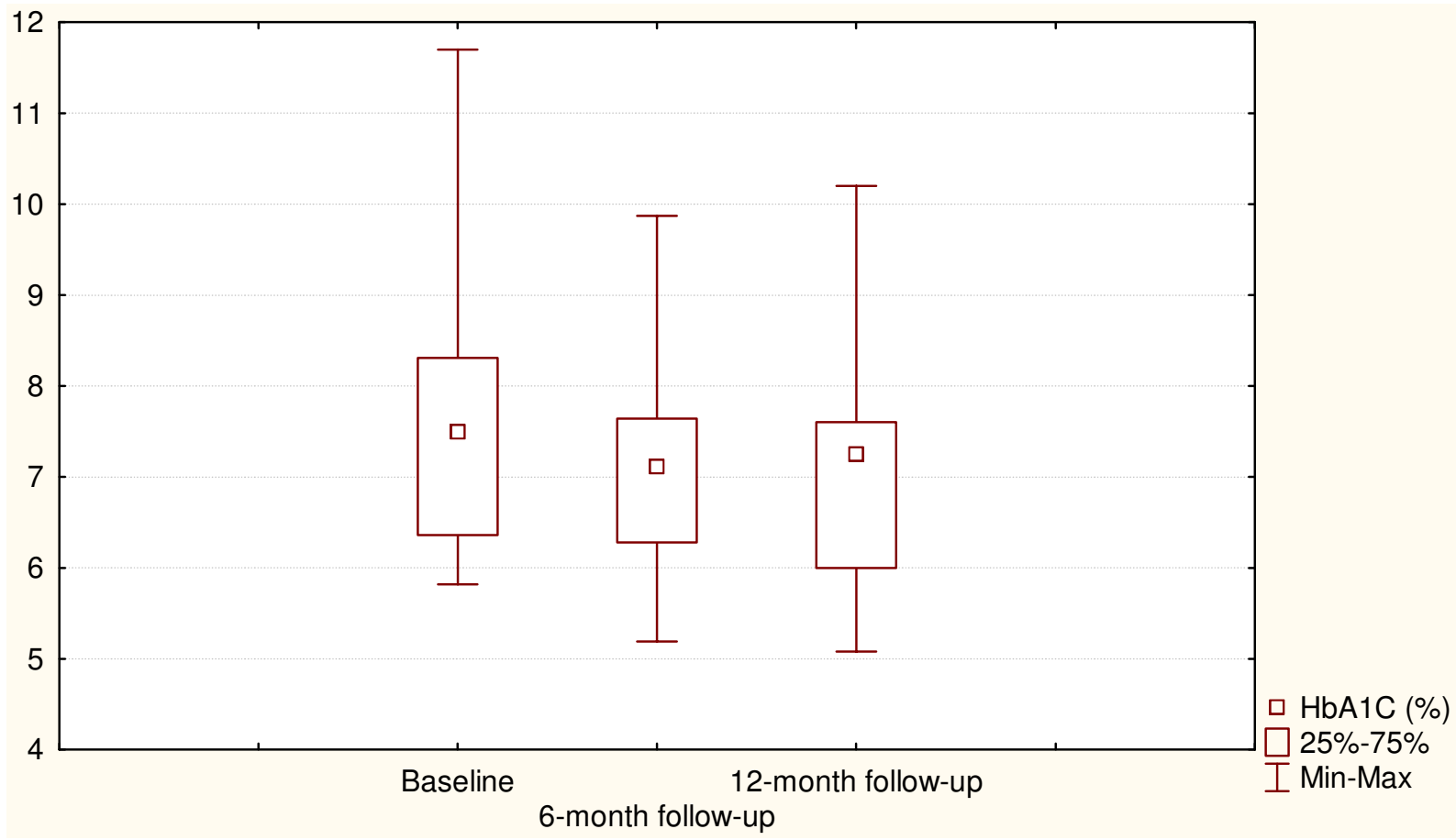

Figure 3

Glycaemic control at baseline and after 6- and I 2-month follow-up (Intervention arm). $\mathrm{X}^{2}=\mathrm{I} \mathrm{I} .6, \mathrm{P}=0.003, \mathrm{Coef}-$ ficient of concordance $=0.34$, Average rank correlation $=0.30$. 


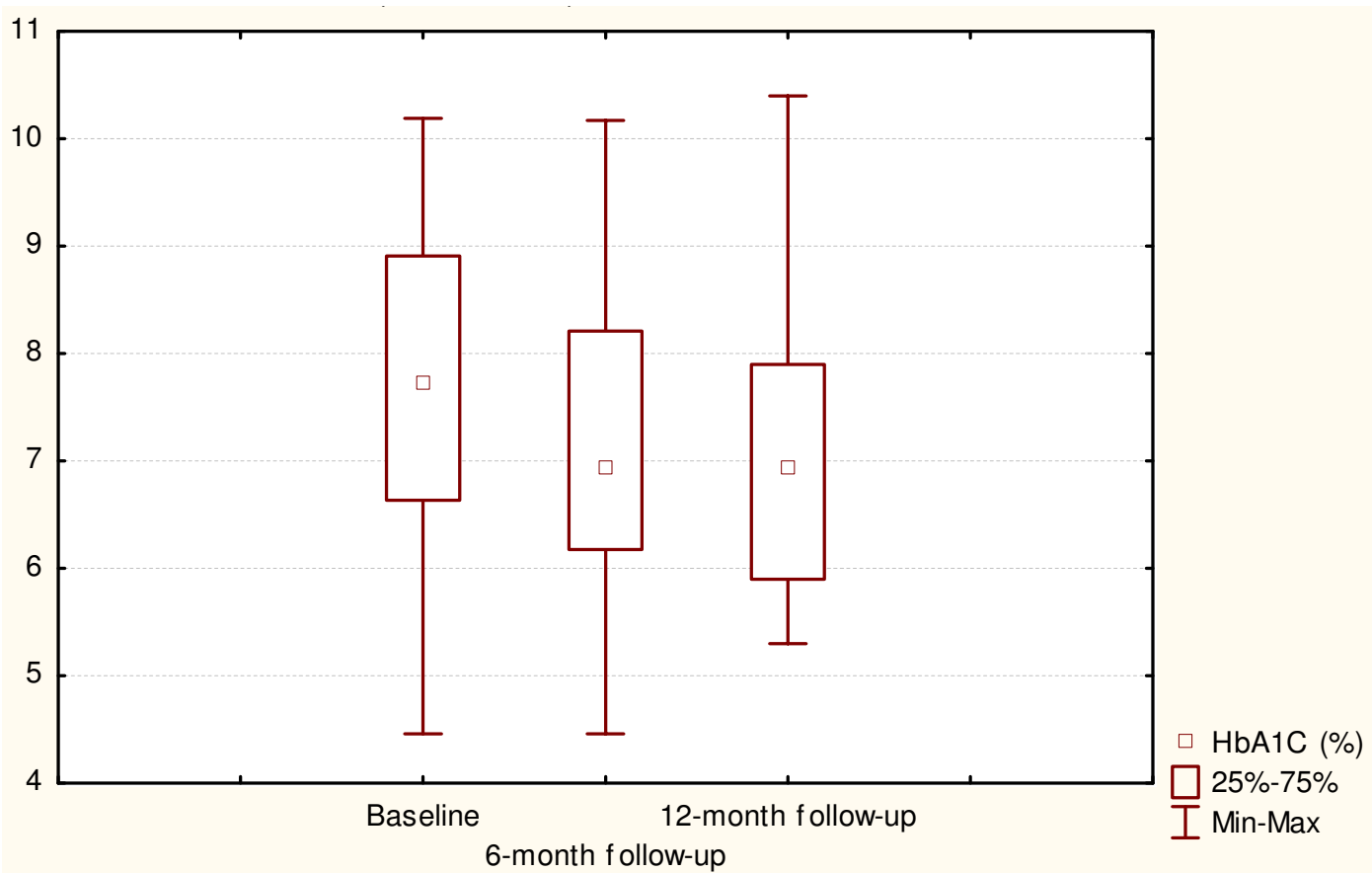

\section{Figure 4}

Glycaemic control at baseline and after 6- and I 2-month follow-up (Control arm). $X^{2}=17.1, p=0.002$, Coefficient of concordance $=0.45$, Average rank correlation $=0.42$.

intervention or in the form of monitoring and followingup its further development, has positive effects on glycaemic control.

A limitation of this preliminary report is its smaller sample size than indicated by the power analysis. However, the preliminary data trend and the qualitative indicators of the patients' benefits gained from participating in the trial make these findings worth reporting.

Although slightly different with respect to education, selfreported adherence to diabetes-specific diet and selfreported physical functioning, the two groups could be considered basically comparable regarding disease-related and psychological variables. In accordance with the literature [34], depressive symptoms in our study participants frequently co-occurred with diabetes-related distress suggesting that focus should be equally on monitoring depressive symptoms and monitoring emotional distress caused by diabetes.

Further research relying on bigger sample sizes is needed to determine whether a psycho-educational intervention may be more efficient than monitoring and following well-being in patients with sub-threshold depression. Inquiring into patients' beliefs about the necessity of treating sub-threshold depressive symptoms, and value- weighted preferences regarding the treatment form may be helpful in determining which patients benefit the most.

\section{Conclusion}

Preliminary data of the randomized controlled trial aimed at comparing the effects of a psycho-educational intervention in patients with mild to moderate depressive symptoms with screening for depression accompanied by a structured follow-up showed comparable improvements in depression- and disease-related variables in both study arms. The findings suggest that monitoring patients' wellbeing within diabetes check-ups, and following those with mild to moderate depressive symptoms could be sufficient at these early stages of depression development.

\section{Competing interests}

The authors declare that they have no competing interests.

\section{Authors' contributions}

MPO is the principal researcher who developed the original idea and design of the study, and drafted the manuscript. ZM participated in planning of the intervention evaluated in the paper. DB, DA and NA participated in data collection and interpretation, as well as in carrying out the study. All authors have read and corrected draft versions, and approved the final version. 


\section{Acknowledgements}

This study was supported by the Ministry of Science, Education and Sports of the Republic of Croatia.

We would like to thank L. Perkovic for her help with the editing of the manuscript.

\section{References}

I. Anderson RJ, Freedland KE, Clouse RE, Lustman PJ: The prevalence of co-morbid depression in adults with diabetes. Diabetes Care 200I, 24: 1069-1078.

2. Black SA, Markides KS, Ray LA: Depression predicts increased incidence of adverse health outcomes in older Mexican Americans with type 2 diabetes. Diabetes Care 2003, 26:2822-2828

3. Ciechanowski PS, Katon WJ, Russo JE: Depression and diabetes: impact on adherence, function and costs. Arch Intern Med 2000 1 60:3278-3285.

4. Lin E, Katon W, von Korrf M, Rutter C, Simon G, Oliver M, Ciechanowski P, Ludman EJ, Bush T, Young B: Relationship of depression and diabetes self-care, medication adherence and preventive care. Diabetes Care 2004, 27:2I 54-2I60.

5. Katon WJ, Lin EH, von Korrf M, Ciechanowski P, Simon G, Ludman $\mathrm{E}$, Bush $\mathrm{T}$, Young B: Cardiac risk factors in patients with diabetes mellitus and major depression. J Gen Intern Med 2004, 19:1192-1199.

6. Lustman PJ, Anderson RJ, Freedland KE, de Groot M, Carney RM: Depression and poor glycemic control: a meta analytic review of the literature. Diabetes Care 2000, 23:434-442.

7. De Groot M, Anderson R, Freedland KE, Clouse RE, Lustman PJ: Association of depression and diabetes complications: a meta-analysis. Psychosom Med 200I, 63:619-630.

8. Katon WJ, Rutter C, Simon G, Lin EH, Ludman E, Ciechanowski P, Kinder L, Young B, Von Korff M: The association of comorbid depression with mortality in patients with type 2 diabetes. Diabetes Care 2005, 28:2668-2672.

9. Goldney RD, Phillips PJ, Fisher LJ, Wilson DH: Diabetes, depression and quality of life. Diabetes Care 2004, 27: I066-1070.

10. Rapaport M, Clary C, Fayyad R, Endicott J: Quality of life impairment in depressive and anxiety disorders. Am J Psychiatry 2005, 162: I |7|-| I78.

II. Judd LL, Akiskal HS, Paulus MP: The role and clinical significance of subsyndromal depressive symptoms (SSD) in unipolar major depressive disorder. J Affect Disorders 1997, 45:5-18.

12. Judd LL, Akiskal HS, Maser JD, Zeller PJ, Endicott J, Coryell W, Paulus MP, Kunovac JL, Leon AC, Mueller TI, Rice JA, Keller MB: A prospective I2-year study of subsyndromal and syndromal depressive symptoms in unipolar major depressive disorders. Arch Gen Psychiatry 1998, 55:694-700.

13. Hegel MT, Oxman TE, Hull JG, Swain K, Swick H: Watchful waiting for minor depression in primary care: remission rates and predictors of improvement. Gen Hosp Psychiatry 2006, 28:205-2I2.

14. Hermens MLM, van Haut HPJ, Terluin B, Windt AWM van der, Beekman ATF, van Dyck $R$, de Haan M: The prognosis of minor depression in the general population. A systematic review: Gen Hosp Psychiatry 2004, 26:453-462.

15. Cuijpers P, Smit F: Subthreshold depression as a risk indicator for major depressive disorder: a systematic review of prospective studies. Acta Psychiatr Scand 2004, I09:325-33I.

16. Sadek N, Bona J: Subsyndromal symptomatic depression: a new concept. Depress Anxiety 2000, I 2:30-39.

17. Cuijpers P, Smit F, Willemse G: Predicting the onset of major depression in subjects with subtreshold depression in primary care: a prospective study. Acta Psychiatr Scand 2004, I I I:133-138.

18. Lyness JM, Heo M, Datto C], Ten Have TR, Katz IR, Drayer R, Reynolds CF, Alexopoulos GS, Bruce ML: Outcomes of minor and subsyndromal depression among elderly patients in primary care settings. Ann Intern Med 2006, I 44:496-504.

19. Paile-Hyvarinen M, Wahlbeck K, Eriksson JG: Quality of life and metabolic status in mildly depressed women with type 2 diabetes treated with paroxetine: a single-blind randomised placebo controlled trial. BMC Fam Pract 2003, 4:7.
20. Trozzolino L, Thomson PS, Tansman M, Azen SP: Effects of a psycho-educational group on mood and glycemic control in adults with diabetes and visual impairments. J Vis Impair Blind 2003, 97:230-239.

21. Kroenke K, Spitzer RL: A new depression and diagnostic severity measure. Psychiatr Ann 2002, 32:509-52I

22. Radloff LS: The CES-D scale: a self-report depression scale for research in the general population. Applied Psychol Meas 1977, 3:385-40I.

23. Welch GW, Jacobson AM, Polonsky WH: The problem areas in diabetes scale. Diabetes Care 1997, 20:760-766.

24. Ware J Jr, Kosinski M, Keller SD: A I2-item short-form health survey: construction of scales and preliminary tests of reliability and validity. Med Care 1996, 34:220-233.

25. Toobert DJ, Hampson SE, Glasgow RE: The Summary of Diabetes Self-Care Activities Measure. Results from 7 studies and a revised scale. Diabetes Care 2000, 23:943-950.

26. Vucic M, Bozicevic S, Mesic R, Cvitkovic L, Rocic B: An automated immunoturbidimetric assay for $\mathrm{HbA}_{\mathrm{lc}}$ determination. Clin Chem Lab Med I999, 37(Special Suppl):SI99.

27. Lewinsohn PM, Antonuccio DO, Steinmetz-Breckenridge JL, Teri L: The Coping with Depression course: A psychoeducational intervention for unipolar depression. Eugene, OR: Castalia Publishing; 1984.

28. Cuijpers P, Munoz RF, Clarke GN, Lewinsohn PM: Psychoeducational treatment and prevention of depression: The "coping with depression" course thirty years later. Clin Psycho Rev 2009, 29:449-458.

29. Pouwer F, Snoek FJ, Ploeg H van der, Ader HJ, Heine RJ: Monitoring of Psychological well_being in outpatients with diabetes. Effects on mood, HbAIC, and the patient's evaluation of the quality of diabetes care: a randomized controlled trial. Diabetes Care 2001, 24:1929-35.

30. Ciechanowski PS, Katon WJ, Russo JE, Hirsch IB: The relationship of depressive symptoms to symptom reporting, self-care and glucose control in diabetes. Gen Hosp Psychiatry 2003, 25:246-252.

31. Trief PM, Morin PC, Izquierdo R, Terese JA, Eimicke JP, Goland R, Starren J, Shea S, Weinstock RS: Depression and Glycemic Control in Elderly Ethnically Diverse Patients with Diabetes. Diabetes Care 2006, 4:830-835.

32. Lustmann PJ, Griffith LS, Freedland KE, Kissel SS, Clouse RE: Cognitive behaviour therapy for depression in type 2 diabetes mellitus. A randomized controlled trial. Ann Intern Med 1998 , 129:|3-2|.

33. Georgiades A, Zucker N, Friedman KE, Mosunic CJ, Applegate K, Lane JD, Feinglos MN, Surwit RS: Changes in depressive symptoms and glycemic control in diabetes mellitus. Psychosom Med 2007, 69:235-24l.

34. Pouwer F, Skinner CT, Pibernik-Okanovic M, Beekman A, Cradock S, Szabo S, Metelko Z, Snoek F: Serious diabetes-specific problems and depression in a Croatian-Dutch-English Survey from the European Depression in Diabetes (EDID) Research Consortium. Diabetes Res Clin Pract 2005, 70:166-173.

Publish with Bio Med Central and every scientist can read your work free of charge

"BioMed Central will be the most significant development for disseminating the results of biomedical research in our lifetime. "

Sir Paul Nurse, Cancer Research UK

Your research papers will be:

- available free of charge to the entire biomedical community

- peer reviewed and published immediately upon acceptance

- cited in PubMed and archived on PubMed Central

- yours - you keep the copyright
BioMedcentral 